\title{
Energy flux density estimation over sea ice based on satellite passive microwave measurements
}

\author{
KONRAD STEFFEN \\ Cooperative Institute for Research in Environmental Sciences, University of Colorado, \\ Campus Box 216, Boulder, CO 80309, U.S.A.
}

\begin{abstract}
This paper discusses in detail the energy flux density estimation at the ice/atmosphere interface over the entire North Water region, based on the ice-type distribution during the winter (1978/79 to $1985 / 86)$. The analysis is based on passive microwave measurements of the scanning multichannel microwave radiometer (SMMR) onboard the Nimbus 7 satellite. Based on the relation of increasing polarization ratio $(18$ or $37 \mathrm{GHz}$ ) with decreasing ice thickness, a threshold technique was applied to classify the different young ice types. The polarization ratio method seems feasible for climatological applications, such as energy flux density estimations, over large areas with homogeneous young ice. More than $20 \%$ young ice $(<0.3 \mathrm{~m})$ was found in the North Water area $\left(100,000 \mathrm{~km}^{2}\right)$ throughout most winters, with maximal values of $60 \%$ and more, and only a few percent of open water were classified. In general, the young ice cover in the North Water was decreasing towards the end of the winter. The mean energy loss for the entire North Water region was found to be $77 \mathrm{~W} \mathrm{~m}^{-2}$ for the months of November to March. Considering an energy supply by refreezing of $38 \mathrm{~W} \mathrm{~m}^{-2}$, the remaining $39 \mathrm{~W} \mathrm{~m}^{-2}$ must be withdrawn from the enthalpy in the sea water.
\end{abstract}

\section{INTRODUCTION}

One of the largest polynyas in the northern hemisphere, if not the largest one, is situated in the North American Arctic between Greenland on the east and the Canadian islands, Ellesmere and Devon, on the west (Fig. 1). In this region, generally known as the North Water, the sea surface does not show an homogeneous ice cover during winter and spring months, as one might expect from the climate conditions in such northern latitudes. On the contrary, an area of loose pack ice is found, formed by the three boundary polynyas of Smith Sound, Lady Ann Strait and Lancaster Sound/ Barrow Strait (Steffen, 1985). To the north, in the narrowest point between Greenland and Canada at $79^{\circ} \mathrm{N}$, the area is bounded by a fast-ice arch. The southern boundary cannot be defined clearly as the pack ice in the North Water is constantly drifting southward. North Water covers an area of approximately $100,000 \mathrm{~km}^{2}$, which is dominated by close pack ice (ice concentration $7 / 10$ to $8 / 10$ ) with open water and thin-ice areas found in leads and the three polynyas in Lancaster Sound, Smith Sound, and Lady Ann Strait throughout winter.

During 1972 to 1981 this area was the focal point of a glacio-climatological expedition aimed at investigating the climatological influence of the North Water on its surroundings. For this reason, during the intensive phase of the project (1972-81), three stations, Coburg Island at

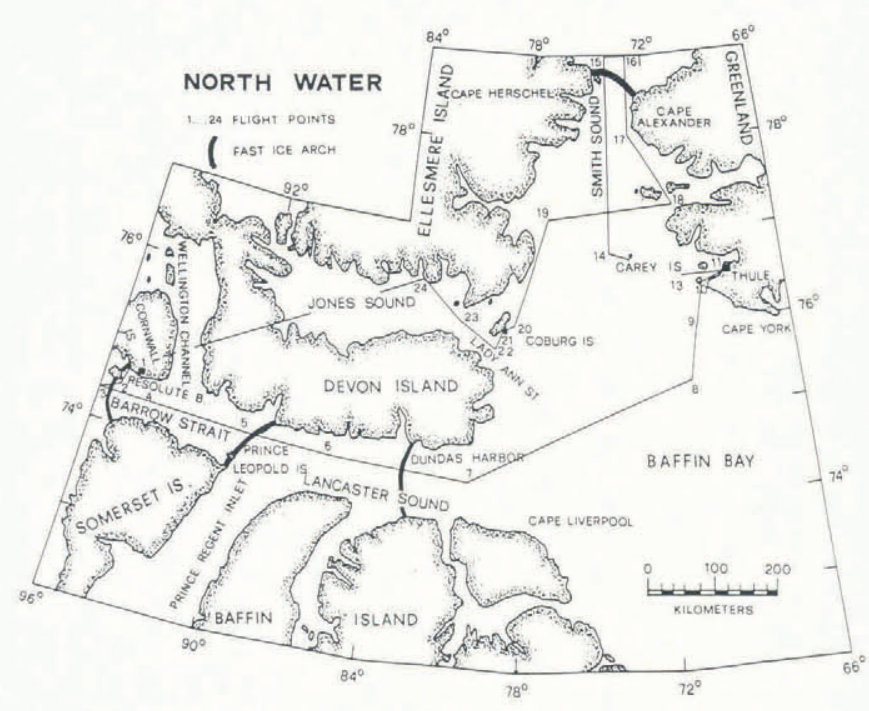

Fig. 1. Map of the North Water area with flight-lines.

the entrance of Jones Sound to Baffin Bay, Carey Islands in the northern Baffin Bay, and Cape Herschel on Ellesmere Island in the northern part of Smith Sound, were manned throughout the year. During this phase, and the subsequent field activities during the summer months until 1981, a number of climatological, glaciological and aerological measurements was carried out. The analysis of 
the station data showed the uniqueness of the climate of northern Baffin Bay, primarily because of the existence of North Water, which is reflected most clearly in the air temperature. Temperatures at the Carey Islands remained higher than at any station during winter. The mean temperature during mid-winter, between December and March, was $-23.0^{\circ} \mathrm{C}$ in $1972-73$ and $-17.5^{\circ} \mathrm{C}$ in $1973-74$. These values are 3 to $10^{\circ} \mathrm{C}$ higher than at the stations on the periphery of the North Water and 10 to $15^{\circ} \mathrm{C}$ higher than at other weather stations in the Canadian Arctic Archipelago. This extremely high winter temperature is evidently due to the convergence of sensible heat released from the surface of the polynyas.

Since no detailed information was available on ice conditions and the extent of open water during winter, radiometric measurements of the sea surface had been taken along $2650 \mathrm{~km}$ of flight-lines from $300 \mathrm{~m}$ in altitude. From November to March 1978-79 and 1980-81, 14 remote sensing flights were carried out using a precision radiation themometer (Barnes PRT-5), in the spectral band 9.5 to $11.5 \mu \mathrm{m}$, to measure the surface temperature along the flight profile (Steffen, 1986). However, ice type and concentrations were never derived for the entire North Water area throughout winter, which is the subject of this analysis.

With the launch of the Nimbus 7 scanning multifrequency microwave radiometer (SMMR) in 1976, the Arctic Ocean surface could be monitored for the first time at different frequencies and polarizations throughout the polar night (Cavalieri and others, 1984; Comiso, 1986; Gloerson and Cavalieri, 1986; Parkinson and others, 1987). The ability of SMMR to acquire imagery of the Earth's surface in most weather and under all lighting conditions makes SMMR particularly useful for sea-ice studies in polar regions. Based on a multi-frequency algorithm using 18 and $37 \mathrm{GHz}$ at vertical and horizontal polarizations, ice concentrations during winter and spring can be derived with a mean difference of $2.5 \%$ (compared to Landsat ice concentration) and a standard deviation of $6.4 \%$ using the NASA-Team algorithm with global tie points (Steffen and Schweiger, unpublished). For the North Water area, the knowledge of the ice-type distribution is important for determining large-scale heat input at the ice-atmosphere boundary. Despite the extremely rapid decrease in energy exchange rates as ice forms in open water, young ice with a thickness of $0.3 \mathrm{~m}$ still has a net heat loss an order of magnitude larger than that of thick first-year ice (Maykut, 1978). The snow cover on sea ice has an insulation effect on conduction. However, recent measurements by Crocker (1984) have shown that the snow cover overlying young ice contains large quantities of salt which increases the thermal conductivity of the snow by up to $50 \%$. In the North Water region, the snow cover on young ice, nilas and new ice usually does not exceed $20 \mathrm{~mm}$ in thickness (Steffen, 1986) and, therefore, the insulation effect of the snow is negligible. For surface energy flux density estimates over polynyas, the percentage of open water and young ice types such as nilas $(0-0.1 \mathrm{~m})$ and grey to grey-white ice $(0.1-0.3 \mathrm{~m})$ are of prime interest.

In the following, a method will be proposed to classify the above-mentioned ice types based on passive microwave satellite measurements. The study area for which the ice-type classification and the corresponding energy flux density estimation was carried out is delineated by longitude $70^{\circ} \mathrm{W}$ and $80^{\circ} \mathrm{W}$ and parallels $72^{\circ} \mathrm{N}$ and $80^{\circ} \mathrm{N}$. The ocean surface in this area comprises approximately $100,000 \mathrm{~km}^{2}$.

\section{METHOD}

\section{Ice typing}

Microwave scattering by sea ice is due to the inhomogeneity of density and structure variations, whereas microwave absorption is determined mainly by the presence of liquid inclusions (brine volume). The relationships between the vertically-polarized brightness temperatures and sea-ice properties such as brine volume or porosity are well known (Mätzler, 1984), whereas the horizontally-polarized brightness temperature is sensitive to surface roughness. In a previous study, it was found that the polarization ratio at 18 and $37 \mathrm{GHz}$ increases with decreasing ice thickness (Steffen and Maslanik, 1988). The polarization ratio is defined as

$$
P R_{f q}=\left(T_{\mathbf{B}}(V, f q)-T_{\mathbf{B}}(H, f q)\right) /\left(T_{\mathbf{B}}(V, f q)+T_{\mathbf{B}}(H, f q)\right),
$$

where $P R_{f q}$ is the polarization ratio at frequency $f q$, $T_{\mathrm{B}}(V, f q)$ and $T_{\mathrm{B}}(H, f q)$ are observed brightness temperatures at frequency $f q$ and vertical or horizontal polarization. In that study, ice types such as white ice (WI: $>0.3 \mathrm{~m}$ thickness), grey and grey-white ice (GI: 0.1 to $0.3 \mathrm{~m}$ thickness), nilas (NI: $<0.1 \mathrm{~m}$ thickness) and open water (OW) were determined visually from Landsat multispectral scanner band 7 (near infrared, 800$1100 \mathrm{~nm}$ ) imagery for the North Water area, and plotted versus the $P R$ of 18 and $37 \mathrm{GHz}$ (Fig. 2). The comparison was made for 260 SMMR grid cells ( 25 by $25 \mathrm{~km}$ ) of the North Water pack ice in spring 1981, for which $100 \%$ of the above specified ice types occurred. The decrease of $P R$

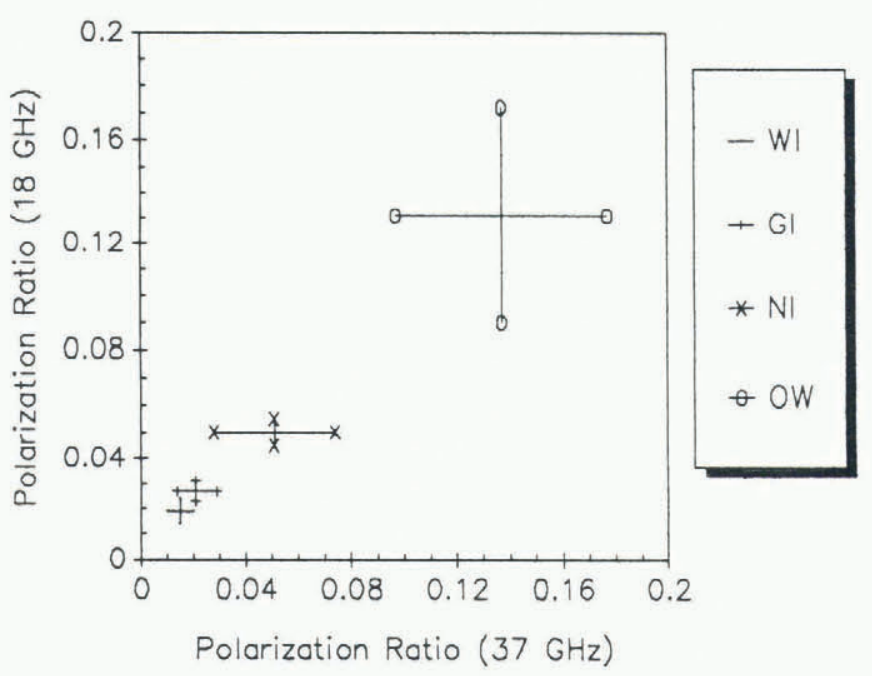

Fig. 2. Passive microwave SMMR polarization ratios ( \pm standard deviation) at 18 and $37 \mathrm{GHz}$, derived by intercomparison with Landsat imagery for white ice (WI), grey ice/grey-white ice (GI), nilas (NI) and open water (OW). 
with increasing ice thickness could be the result of the reduction in brine volume when the ice becomes thicker and colder; in other words, the sensitivity of the verticallypolarized brightness temperature to the decrease in salinity. Large variabilities of horizontal polarization are caused by surface roughness on a small scale (Mätzler, 1984). However, by averaging over a large area (one SMMR pixel), the scatter may be smeared out, and the average value resulting from the thin snow cover and the young ice in the North Water may not be influenced by the disturbing effect.

The standard deviations of open water, nilas and grey ice do not overlap for $18 \mathrm{GHz}$, indicating that a classification of these ice types based on satellite-derived $P R$ may be possible over fully-consolidated ice (Fig. 2). For grey ice and white ice the standard deviations at the same frequency show a small overlap. For $37 \mathrm{GHz}$, only water and nilas can be classified using the $P R$ method with a certain degree of confidence; white ice, grey ice and, to some degree, nilas show a considerable overlap of the $P R$ standard deviations. The larger standard deviation at $37 \mathrm{GHz}$, compared to $18 \mathrm{GHz}$, could be explained by the larger sensitivity of $37 \mathrm{GHz}$ to water vapour; microwave absorption and zenith opacity is three times more sensitive to water vapour at $37 \mathrm{GHz}$ compared to $18 \mathrm{GHz}$ (Walters, 1976). The standard deviations of open water show a broad range that can be explained by the presence of small ice floes not resolved in the Landsat imagery and by the brightness temperature change due to wind-induced spray and foam on the ocean surface.

Similar $P R$ values for the above-mentioned ice types were reported by Cavalieri and others (1986) for aircraft measurements in the Bering Sea and by Grenfell (1986) for ground-based measurements from the Greenland Sea. Radiometric observations of sea-ice growth in a tank also showed a decrease of $P R$ with increasing ice thickness. However, the $P R$ reached a limiting value when ice thickness was 20 to $25 \mathrm{~mm}$ at air temperatures between $-2^{\circ}$ to $-15^{\circ} \mathrm{C}$ (Grenfell and Comiso, 1986). Their study also showed significant changes in $P R$ even though the ice thickness was nearly the same, while the air temperature changed by several degrees. For the North Water sea ice, brine volume is assumed to be higher than during the Grenfell and Comiso tank experiment due to the lower air temperatures of $-20^{\circ}$ to $-30^{\circ} \mathrm{C}$, resulting in a larger difference between horizontally- and vertically-polarized brightness temperatures.

Based on the relation of increasing polarization ratio with decreasing ice thickness, as verified with the Landsat comparison for the North Water area, a threshold technique was applied to classify the different ice types. For the ice typing presented in this paper, the following $P R$ values were used for 18 and $37 \mathrm{GHz}$ :
$37 \mathrm{GHz}$ :
$18 \mathrm{GHz}$ :
$0.086<\mathrm{OW}$
$0.071<\mathrm{OW}$
$0.085>\mathrm{NI}>0.031$
$0.070>\mathrm{NI}>0.041$
$0.030>$ GI $>0.019$
$0.040>$ GI $>0.023$
$0.018>\mathrm{WI}$
$0.022>$ WI

The $18 \mathrm{GHz}$ is less affected by water vapour (see the smaller standard deviation in Figure 2) and, therefore, is preferable for applications over polynyas with large amounts of low level clouds due to extensive latent energy flux density. However, the SMMR pixel at $18 \mathrm{GHz}$ has a field of view of 60 by $60 \mathrm{~km}$, which represents only $50 \%$ of the actual power received by the radiometer. The $37 \mathrm{GHz}$ frequency has a field of view of approximately 25 by $25 \mathrm{~km}$, which seems more realistic for young ice classification in polynyas. In the following analysis, the $37 \mathrm{GHz} P R$ were used for ice-type classification despite the larger uncertainty due to the considerable overlapping of the $P R$ standard deviation for the different ice types. For winter pack-ice conditions, with a small fraction of open water and thin ice, this method may give erroneous results because the SMMR pixel of $25 \mathrm{~km}$ in dimension is certainly larger than the thin-ice areas. To address this problem, the $P R$ of mixed-ice SMMR pixels was analyzed. All SMMR pixels consisting of white ice/ grey ice (WIGI), white ice/nilas (WINI), white ice/open water (WIOW) and grey ice/nilas (GINI), of which each ice type (e.g. WI and GI) covered $50 \%$ of the SMMR pixel, were classified according to the Landsat data. The $P R$ at 18 and $37 \mathrm{GHz}$ are given in Figure 3. Also shown in the figure are the mean $P R$ values for the three ice types and open water. If we compare mean $P R$ only, GI and WIGI signatures are almost identical and, therefore, a clear distinction of ice types and ice-type mixtures within one SMMR pixel is not possible. This is the major shortcoming of this proposed $P R$ ice-type classification method and limits its application to large homogeneous ice areas consisting of a single ice type which is often found in large polynyas such as the North Water.

\section{Energy flux density parameterization}

The method for energy flux density calculation for different first-year ice types is described in detail by Maykut (1986). Young ice ( $<0.3 \mathrm{~m}$ thick) still has a large conductive energy flux density at the ice/atmosphere interface (Fig. 4). Therefore, not only ice-free areas are of importance for energy flux density calculations over packice regions. The oceanic energy flux density, the only

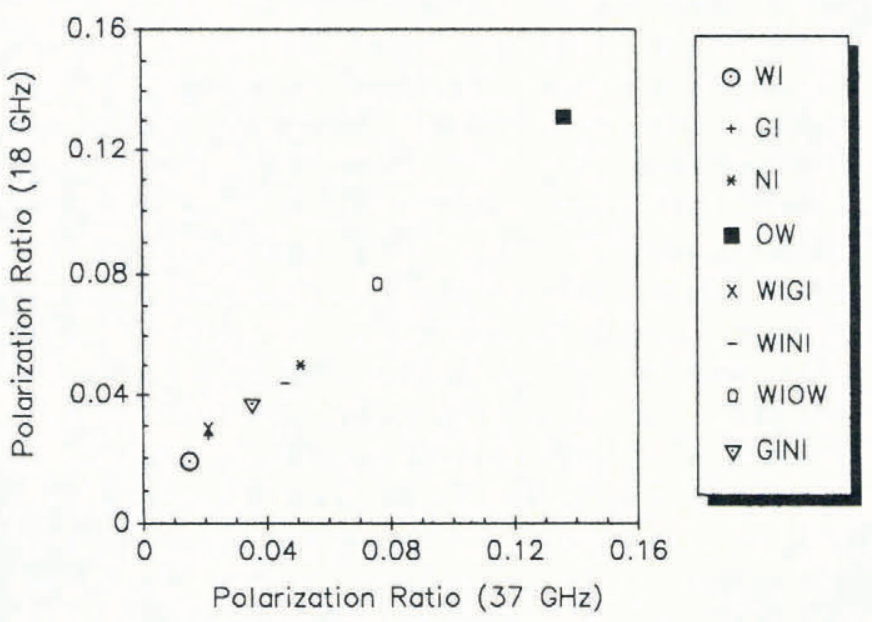

Fig. 3. Mean polarization ratios at 18 and $37 \mathrm{GHz}$, derived by intercomparison of Landsat and SMMR data for white ice (WI), grey ice/grey-white ice (GI), nilas (NI), open water (OW) and for mixed-ice SMMR pixels for white icel grey ice (WIGI), white ice/nilas (WINI), white ice/open water (WIOW) and grey ice/nilas (GINI). 
Steffen: Passive microwave measurements of sea ice

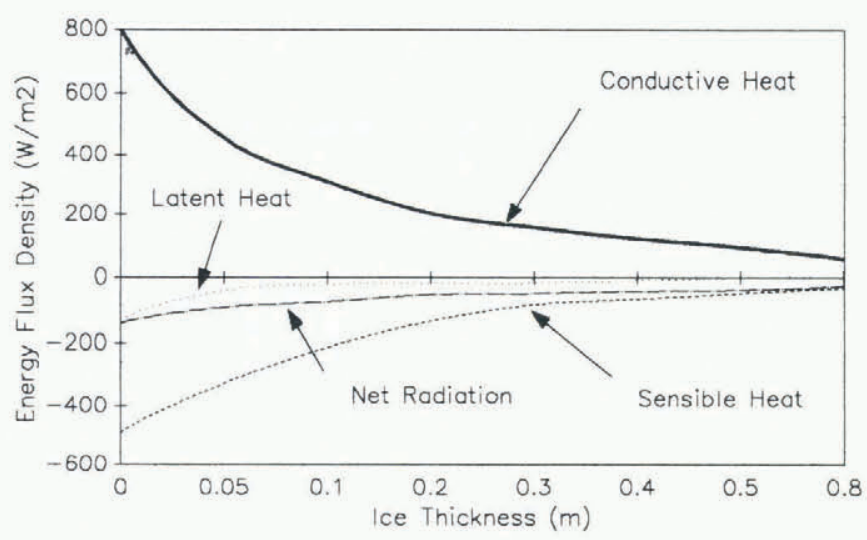

Fig. 4. Energy flux density and ice thickness at the ice/ atmosphere interface in January for an air temperature of $-30^{\circ} \mathrm{C}$ (after Maykut, 1986; Steffen, 1986).

energy source over Arctic winter pack ice, amounts to $840 \mathrm{~W} \mathrm{~m}^{-2}$ in ice-free regions and, as conductive energy flux density, to approximately $125 \mathrm{~W} \mathrm{~m}^{-2}$ for young ice areas (Fig. 4). Similar results were found during the in situ North Water energy flux density measurements over thin ice (Steffen, 1986). The conductive energy flux density decreases to about $20 \mathrm{~W} \mathrm{~m}^{-2}$ for ice of $2 \mathrm{~m}$ thickness. The sensible energy flux density in the air, which comprises approximately $60 \%$ of the energy loss over young ice, depends mainly on the ambient air temperature and to a minor degree also on the wind speed. For the calculation of the sensible energy flux density rates of different ice types, the monthly mean air temperatures for the North Water region from our three expedition stations located within that region were used (North Water expedition data archive, ETH, Zürich, Switzerland). The five-year data set showed a small interannual variability of the mean monthly air temperature for the months October to March (standard deviation range: $\pm 0.5^{\circ}$ and $\pm 1.7^{\circ} \mathrm{C}$ ), and therefore, these mean values were applied for the entire time-period shown in this study. For white ice, a mean thickness of $0.8 \mathrm{~m}$ was assumed with a snow cover of $50 \mathrm{~mm}$. The overall energy balance for the North Water region depends only little on the thickness distribution of WI. A sensitivity study showed that an increase in ice thickness by $0.2 \mathrm{~m}$ reduced the energy balance by $5 \%$ when a snow cover of $50 \mathrm{~mm}$ was assumed. The calculated energy flux density rates for the ice types nilas, grey ice, white ice, and open water, together with air temperatures for the months November to March, are plotted in Figure 5. Also shown in Figure 5 is the mean monthly air temperature for the North Water region.

\section{RESULTS AND DISCUSSION}

The ice types were classified within the ocean surface of the study area $\left(100,000 \mathrm{~km}^{2}\right)$ according to the method described above. The Smith Sound, Lady Ann Strait, and Lancaster Sound polynyas, also located within this study area, vary in size considerably throughout winter. The panels in Figure 6 give the cumulative ice-type percentages for white ice (WI), grey ice/grey-white ice (GI), nilas (NI) and open water (OW) on alternative days for the

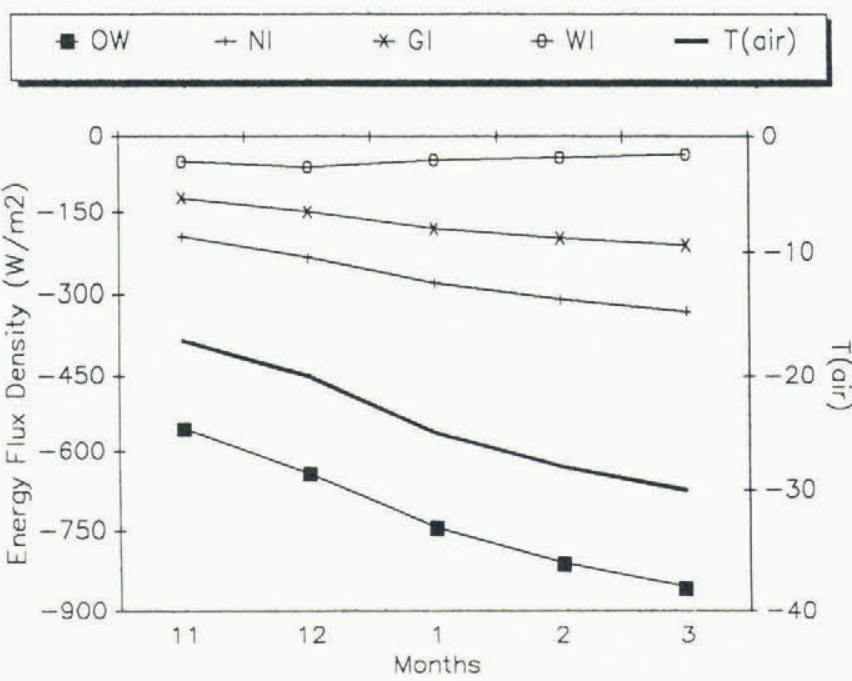

Fig. 5. Total energy flux density rates (sensible energy flux density, latent energy flux density and long-wave radiation balance) over four different ice types (white ice, grey/greywhite ice, nilas, and open water) during the winter months November to March. The right abscissa shows the local air temperature for the North Water region, as derived from the North Water climate data archive (ETH, Zürich, Switzerland).

winter months November to March of $1978 / 79$ to $1985 / 86$. The right abscissa gives the corresponding total energy flux density based on energy flux density parameterization for ice types and open water.

More than $20 \%$ young ice $(<0.3 \mathrm{~m})$ was found during October to March for most winters, with maximum values of $60 \%$ and more. In general, the young ice cover in the North Water was decreasing towards the end of the winter. Only a few percent of open water were classified throughout the winter, which is in good agreement with the low-level aircraft measurements carried out during the winter 1980/81 (Table 1). The large difference between SMMR-derived open water and the flight measurement (2 December 1980, Table 1)

Table 1. Open Water (OW) derived from $37 \mathrm{GHz}$ passive microwave SMMR data for the North Water area $\left(100,000 \mathrm{~km}^{2}\right)$, compared with open water measured along the flight profile (percent of $1,500 \mathrm{~km}$ flight profile) from $300 \mathrm{~m}$ altitude with a precision radiation thermometer (PRT. 5). The flight profile is given in Figure 1.

Date Julian Day OW OW

(SMMR) (Flight profile)

$\begin{array}{lrrr}12 / 2 / 1980 & 336 & 0 \% & 5.5 \% \\ 12 / 20 / 1980 & 354 & 1.3 \% & 2.9 \% \\ 12 / 29 / 1980 & 363 & 0 \% & 0.3 \% \\ 1 / 22 / 1981 & 22 & 3.3 \% & 4.2 \% \\ 2 / 7 / 1981 & 38 & 1.3 \% & 0 \% \\ 3 / 7 / 1981 & 66 & 0 \% & 0 \%\end{array}$



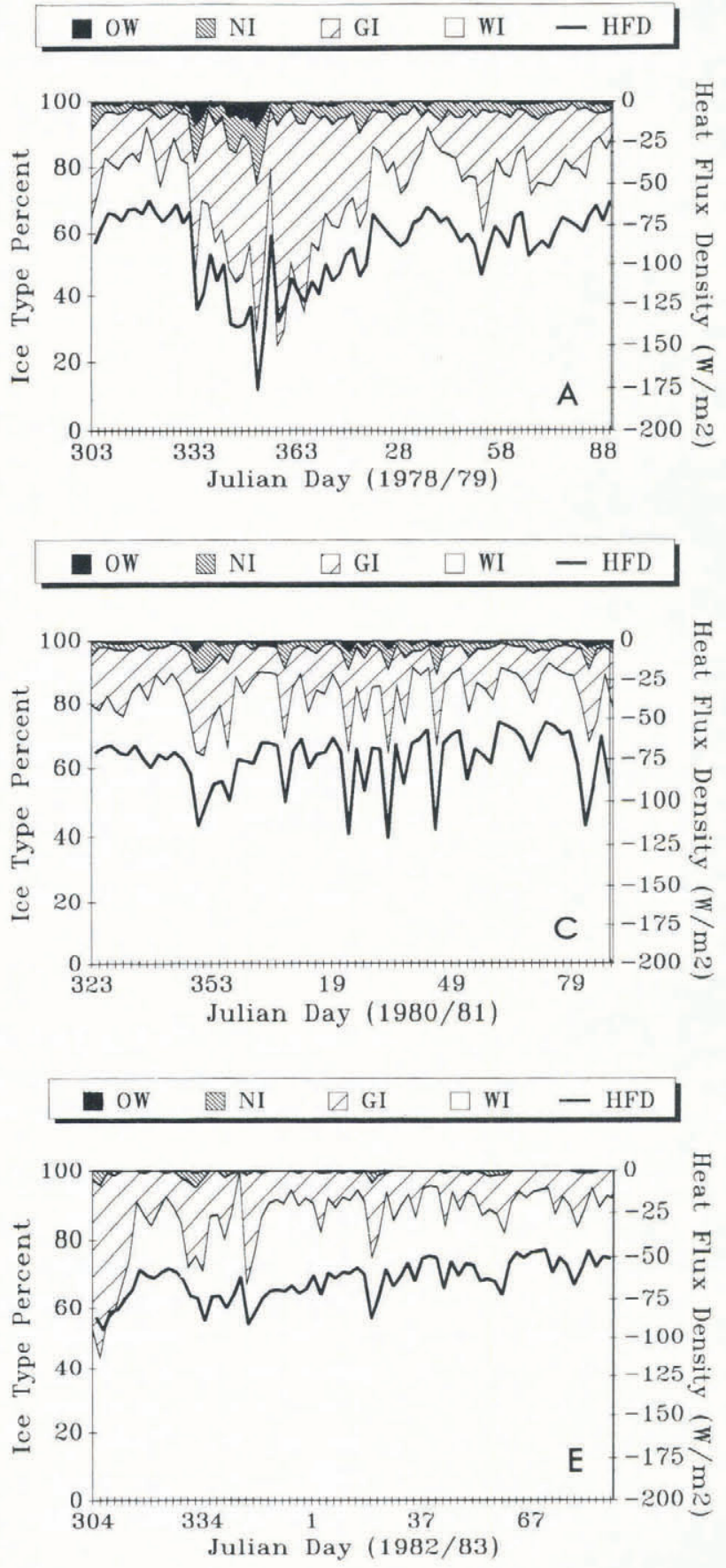

\begin{tabular}{lllll}
\hline OW & $\mathbb{N}$ & $\mathrm{NI}$ & $\square \mathrm{GI}$ & $\square \mathrm{WI}$
\end{tabular}

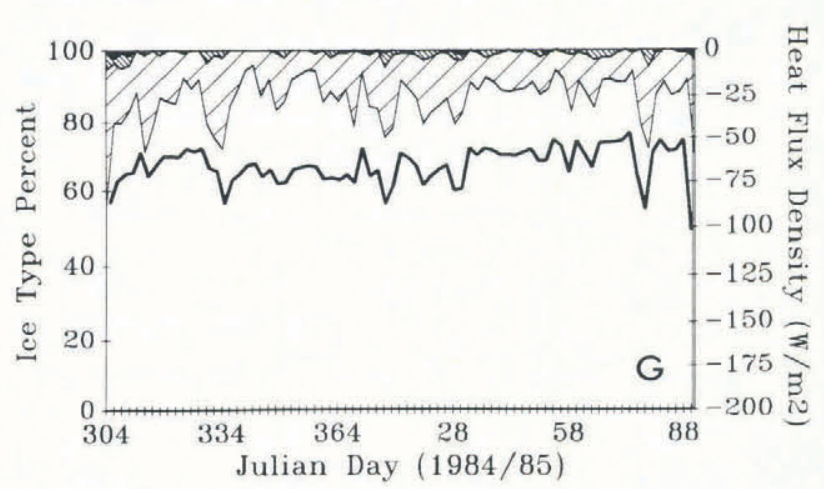

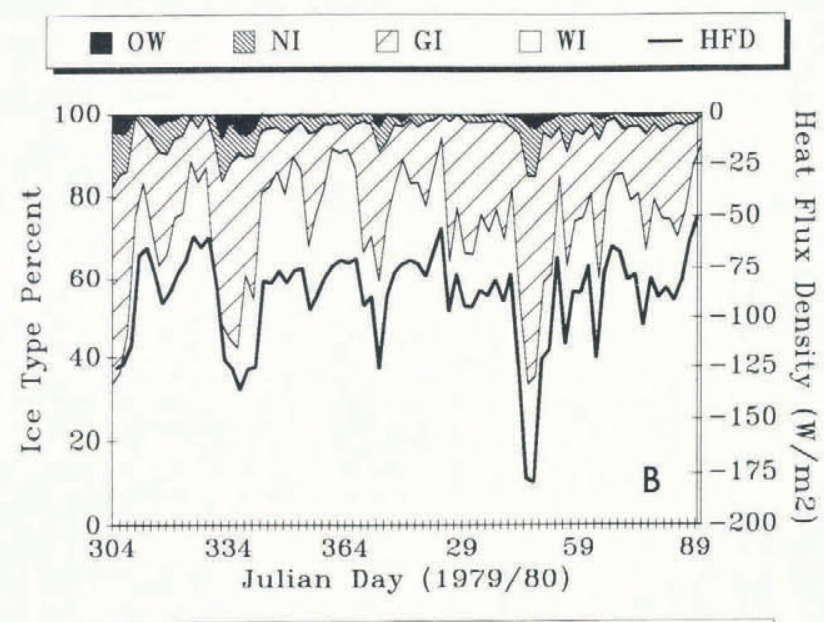
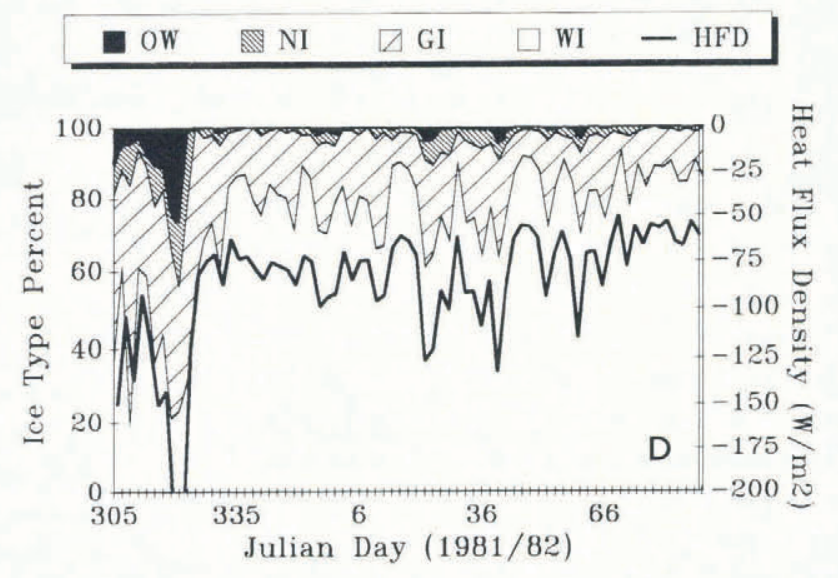

\begin{tabular}{lllll}
\hline $\mathrm{OW}$ & $\mathbb{N} \mathrm{NI} \quad \square \mathrm{GI}$ & $\square \mathrm{WI}$ & $-\mathrm{HFD}$ \\
\hline
\end{tabular}
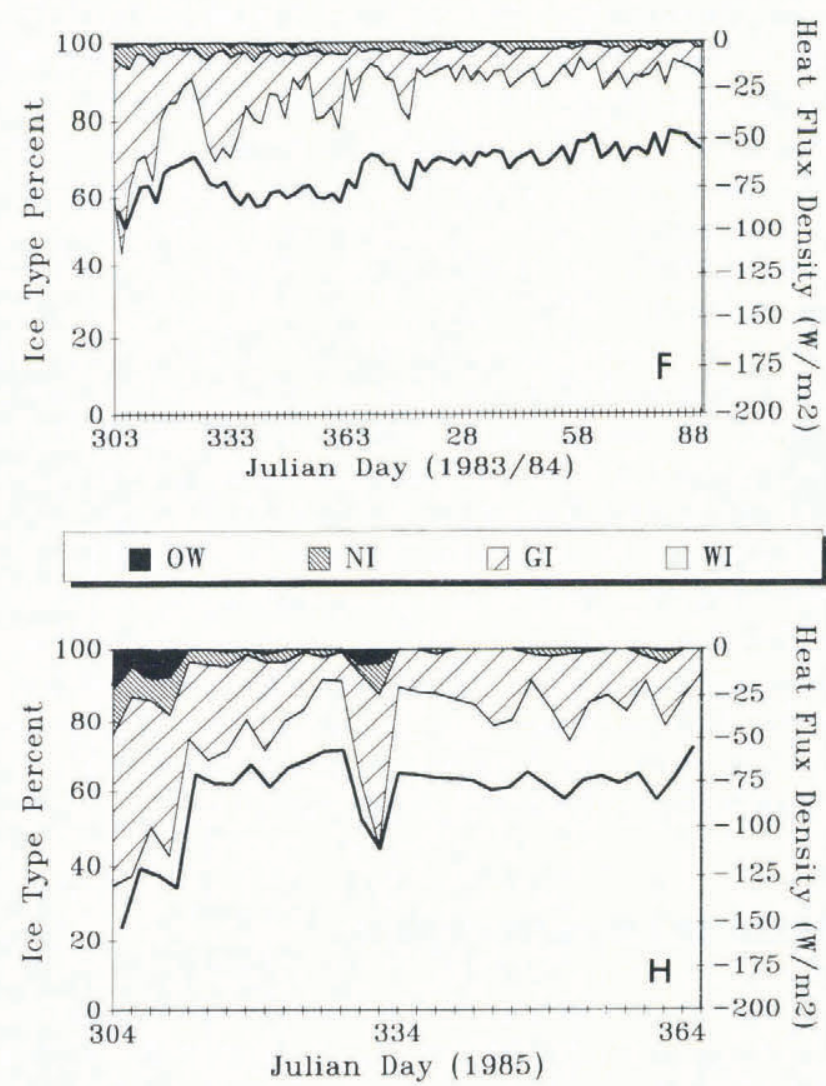

Fig. 6. Cumulative ice-type percentage for white ice (WI), grey/grey-white ice (GI), nilas (NI), and open water (OW) derived from SMMR passive microwave data $(37 \mathrm{GHz}$ polarization ratios) for the North Water area $\left(100,000 \mathrm{~km}^{2}\right)$, winter $1978 / 79$ to $1985 / 86$. The right abscissa shows the total energy flux density (sensible energy flux density, latent energy flux density and long-wave radiation balance) derived from the ice-type percentage of the North Water area. 
depicts the limitation of the low-resolution passive microwave method, as all open water areas were located along the Greenland coast within the ocean/land SMMR pixel of $25 \mathrm{~km}$.

The most striking phenomenon is the pulse-like change of ice types throughout winter, which could be explained by strong northerly storms occurring in this region. Wind measurements at Cape Sabine (western side of Smith Sound) carried out during the North Water expedition from November to March (1974 to 1977) showed a predominantly northerly component with a mean wind speed of $8.7 \mathrm{~m} \mathrm{~s}^{-1}$ from the north-northwest (Steffen, 1985). During this period, 14 gales with wind speeds greater than $20 \mathrm{~m} \mathrm{~s}^{-1}$ from the north-northwest were observed. These storms lasted for a total of 270 hours, with maximum wind speeds as high as $40 \mathrm{~m} \mathrm{~s}^{-1}$. On the average, every tenth day a storm occurred with a mean duration of 19 hours. Because of the ice divergence caused by the wind-induced ice drift of approximately $17 \mathrm{~km} \mathrm{~d}^{-1}$, the mean duration of stay of sea ice in Smith Sound (northern part of the North Water) between October and March is less than one week. These predominantly northerly winds, that are channeled in the Smith Sound (Ito, 1982), account for the ice drift which generates open water areas where young ice can grow. The fact that the open water and young ice peaks (maximum extent) occur almost at the same time is due to the size of the study area. A separate study (not shown here) indicated that there is a time lag of two to four days between the maximum extents of open water and young ice.

The supply of heat from the sea water and the latent heat of ice formation is compensated by the loss of energy due to sensible heat, latent heat and long-wave radiation. This total energy loss due to open water and thin ice is shown in Table 2 (mean for five months period) and in Figure 6. The mean energy loss for the entire North Water region was found to be $77 \mathrm{~W} \mathrm{~m}^{-2}$ for the months November to March. Ice formation of $20 \mathrm{mmd}^{-1}$ was found from ice-thickness measurements in this area (Steffen, 1986). Using Schwerdtfeger's (1963) equation for latent heat for sea-ice formation with a mean salinity of $16 \%$ for the lowest $50 \mathrm{~mm}$ of ice, the supply of heat by refreezing is $38 \mathrm{~W} \mathrm{~m}^{-2}$ at the most. The remaining $39 \mathrm{~W} \mathrm{~m}^{-2}$ must be withdrawn from the enthalpy in the sea water.

Table 2. Mean energy loss of the North Water surface due to sensible heat, latent heat and long-wave radiation. Calculation based on energy flux density rate parameterization for different ice types.

\begin{tabular}{cccc}
\hline Year & $\begin{array}{c}\text { Min } \\
\left(\mathbf{W ~ m}^{-2}\right)\end{array}$ & $\begin{array}{c}\text { Max } \\
\left(\mathbf{W ~ m}^{-2}\right)\end{array}$ & $\begin{array}{c}\text { Mean } \\
\left(\mathbf{W ~ m}^{-2}\right)\end{array}$ \\
\hline $1978 / 79$ & -60 & -176 & -89 \\
$1979 / 80$ & -50 & -179 & -89 \\
$1980 / 81$ & -52 & -120 & -75 \\
$1981 / 82$ & -50 & -233 & -87 \\
$1982 / 83$ & -46 & -94 & -63 \\
$1983 / 84$ & -45 & -97 & -65 \\
$1984 / 85$ & -46 & -101 & -65 \\
$1985 / 86 *$ & -55 & -152 & -81 \\
\hline
\end{tabular}

*only November and December

\section{ACKNOWLEDGEMENTS}

This research was funded under contract NAG $5-882$ by NASA Ocean Sciences Branch. Additional support was provided by the Swiss Federal Institute of Technology. Thanks are due to Jim Maslanik, National Snow and Ice Data Center at the University of Colorado, for providing the time series of the SMMR data.

\section{REFERENCES}

Cavalieri, D.J., P. Gloersen, and W.J. Campbell. 1984. Determination of sea ice parameters with the NIMBUS 7 SMMR. 7. Geophys. Res., 89(D4), 5355-5369.

Cavalieri, D.J., P. Gloersen, and T.T. Wilheit, Fr. 1986. Aircraft and satellite passive microwave observations of the Bering Sea ice cover during MIZEX West. IEEE Trans. Geosci. Remote Sensing, GE-24(3), 368-377.

Comiso, J.C. 1986. Characteristics of Arctic winter sea ice from satellite multispectral microwave observations. $\mathcal{F}$. Geophys. Res., 91(C1), 975-994.

Crocker, G.B. 1984. A physical model for predicting the thermal conductivity of brine-wetted snow. Cold Reg. Sci. Technol., 10(1), 69-74.

Gloersen, P. and D.J. Cavalieri. 1986. Reduction of weather effects in the calculation of sea ice concentration from microwave radiances. F. Geophys. Res., 91(C3), 3913-3919.

Grenfell, T.C. 1986. Surface-based passive microwave observations of sea ice in the Bering and Greenland seas. IEEE Trans. Geosci. Remote Sensing, GE-24(3), 378-382.

Grenfell, T.C. and J.C. Comiso. 1986. Multifrequency passive microwave observations of first-year sea ice grown in a tank. IEEE Trans. Geosci. Remote Sensing, GE24(6), 826-831.

Ito, H. 1982. Wind through a channel surface: wind measurements in Smith Sound and Jones Sound in the northern Baffin Bay. J. Appl. Meteorol., 21, 1053-1062.

Mätzler, C., R.O. Ramseier, and E. Svendsen. 1984. Polarization effects in sea-ice signatures. IEEE J. Oceanic Eng., OE-9(5), 333-338.

Maykut, G.A. 1978. Energy exchange over young sea ice in the central Arctic. F. Geophys. Res., 83(C7), 36463658.

Maykut, G.A. 1986. The surface heat and mass balance. In Untersteiner, N., ed. The geophysics of sea ice. New York and London, Plenum Press, 395-463.

Parkinson, C.L., J.C. Comiso, H.J. Zwally, D.J. Cavalieri, P. Gloersen, and W.J. Campbell. 1987. Arctic sea ice, 1973-1976: satellite passive-microwave observations. Washington, DC, National Aeronautics and Space Administration. (NASA SP-489.)

Schwerdtfeger, P. 1963. The thermal properties of sea ice. 7. Glaciol., 4(36), 789-807.

Steffen, K. 1985. Warm water cells in the North Water, northern Baffin Bay during winter. 7. Geophys. Res., 90(C5), 9129-9136.

Steffen, K. 1986. Ice conditions of an Arctic polynya: North Water in winter. F. Glaciol., 32(112), 383-390.

Steffen, K. and J.A. Maslanik. 1988. Comparison of geophysical sea ice parameters derived from passive microwave data and Landsat imagery for the North Water area of Baffin Bay. F. Geophys. Res., 93(C9), $10,769-10,781$.

Steffen, K. and A. Schweiger. In press. DMSP-SSM/I NASA algorithm sea ice retrieval comparison with Landsat satellite imagery. 7. Geophys. Res.

The accuracy of references in the text and in this list is the responsibility of the author, to whom queries should be addressed. 